\title{
The factors affecting MTC of thorium-plutonium-fuelled PWRs
}

\author{
Nurjuanis Zara Zainuddin, Geoffrey T. Parks*, Eugene Shwageraus \\ Department of Engineering, University of Cambridge \\ Cambridge, CB2 1PZ, United Kingdom \\ Phone: +441223748553 \\ Fax: +44 1223 332662
}

\begin{abstract}
Plutonium loading in a plutonium-thorium $(\mathrm{Pu}-\mathrm{Th})$ mixed oxide (MOX) fuelled pressurized water reactor (PWR) core is typically constrained by large maximum radial form factors (RFF) and positive moderator temperature coefficient (MTC). The large form factors in higher $\mathrm{Pu}$ content fuels stems from the large differences in burnup, and thus reactivity, between fresh and burnt fuel, while positive MTC can potentially be the result of the high soluble boron concentrations needed to maintain criticality for such reactive fuel. The conventional solution to these problems is the use of burnable poisons (BPs). While BPs are able to reduce RFF, the positive MTC is not entirely due to a large critical boron concentration (CBC) requirement. In fact, analysis shows a positive MTC in Th-Pu fuel is mainly caused by fissioning in the epithermal-fast energy range. A reduction in epithermal-fast fissioning through the use of certain BPs and the strategic employment of loading patterns that encourage leakage are more effective in attaining negative MTC, as a reduction in CBC has a negligible effect on MTC. This paper examines the contributions to positive MTC by isotope and energy and identifies characteristics of BPs that are able to mitigate positive MTC in a Pu-Th MOX PWR core.
\end{abstract}

Keywords: Thorium, plutonium, in-core fuel management, burnable poisons, MTC

\section{Introduction}

Plutonium $(\mathrm{Pu})$ and minor actinides (MAs) present a significant nuclear proliferation concern as well as contributing to the long-term radiotoxicity of nuclear waste. There is a large amount of separated civil plutonium available today, with the largest stockpile in the world situated in the UK (Broomby, 2013).

With the delay in the deployment of fast reactors, the option to incinerate $\mathrm{Pu}$ in thermal reactors that are already widely in use is an attractive one. Typically, this is performed by mixing uranium (U) with $\mathrm{Pu}$ as mixed oxide (MOX) fuel (IAEA, 2003, Haas and Hamilton,

\footnotetext{
${ }^{*}$ Corresponding author

Email address: gtp10@cam.ac.uk (Geoffrey T. Parks)
} 
2007). An alternative approach is to use thorium (Th) as a fertile isotope instead of U. This increases the $\mathrm{Pu}$ incineration rate, as additional $\mathrm{Pu}$ is not bred from ${ }^{238} \mathrm{U}$, although fissile ${ }^{233} \mathrm{U}$ is bred instead. Multiple lattice-physics-based investigations have confirmed this behaviour in pressurized water reactors (PWRs), e.g. studies by Galperin (1995) and Shwageraus et al. (2004), and such fuel has been shown to be feasible in a whole core (Fridman and Kliem, 2011). Additionally, the Th-Pu matrix also shows potential for reducing radiotoxicity and decay heat when compared with standard U fuel waste (Wang et al., 2003; Hesketh, 2013). This offers an economic gain as it allows better management of spent fuel in repositories.

Plutonium incineration can be pursued with either of the following competing objectives:

- Fast burn: Burn Pu quickly, i.e. increasing the rate of Pu incineration.

- Deep burn: Burn as large a fraction of the initially loaded Pu as possible, i.e. reducing the final amount of $\mathrm{Pu}$ in fuel.

A fast burn of $\mathrm{Pu}$ is achieved by decreasing the power share of all other nuclides (such as ${ }^{233} \mathrm{U}$ from the Th chain) in favour of primarily burning $\mathrm{Pu}$, fast. Conversely, a deep burn means maximising the conversion of Th to ${ }^{233} \mathrm{U}$, the presence of which will extend burnup of the fuel and allow more $\mathrm{Pu}$ to burn over time. However, a high $\mathrm{Pu}$ loading is required to sustain criticality as ${ }^{233} \mathrm{U}$ builds up slowly. The amount of $\mathrm{Pu}$ that can be loaded is limited by operational constraints on the maximum radial form factor (RFF) and prohibiting a positive moderator temperature coefficient (MTC).

Technically, there is no explicit requirement to keep the MTC negative at all operating conditions. The US NRC General Design Criterion No. 11 (NRC, 2016), for example, states: "The reactor core and associated coolant systems shall be designed so that in the power operating range, the net effect of the prompt inherent nuclear feedback characteristics tends to compensate for a rapid increase in reactivity. (This is negative feedback on a power transient)." However, a negative MTC requirement was imposed in this study to provide conservatism since detailed transient analysis was out of scope at this stage.

The large form factors in higher $\mathrm{Pu}$ content fuels stem from the large differences in burnup between fresh and burnt fuel.

A positive MTC, on the other hand, can potentially be the result of the high soluble boron concentrations needed to maintain criticality for such reactive fuel due to a harder spectrum and reduced boron worth. The conventional solution to these problems is the use of burnable poisons (BPs).

This study investigates the contributions (by isotope and energy range) to positive MTC in high $\mathrm{Pu}$ content fuel. It then identifies characteristics of BPs that are able to mitigate positive MTC and presents potential BPs that can be used for this purpose.

\subsection{Th-Pu fuel in PWRs}

Fast reactors have not been widely commercially implemented yet. Hence the majority of spent nuclear fuel discharged from commercial reactors, which would have otherwise been efficiently incinerated in fast reactors, is now either due for interim storage, recycling, or direct final disposal. Civil Pu is recycled in some European countries (e.g. France, Belgium) 
while the United States and Russia have examined the option of incinerating their dismantled nuclear warheads (weapons-grade $\mathrm{Pu}$ ). However, the presence of uranium (specifically ${ }^{238} \mathrm{U}$ ) in conventional MOX fuel for the purpose of incinerating $\mathrm{Pu}$ means that $\mathrm{Pu}$ production can only be constrained, rather than being significantly reduced in content. Thus, the use of non-uranium fuels became of interest - inert-matrix (or fertile-free) fuel and thorium (Th). This work examines the use of thorium.

Over the years, interest in thorium has waxed and waned, with two recurring motivations for considering use of this fuel:

- Reducing the risk of nuclear weapons proliferation: Either in the form of using thorium with uranium, creating ${ }^{233} \mathrm{U}$, which has self-protecting gamma-emitting daughter products in the decay chain of accompanying ${ }^{232} \mathrm{U}$, or incinerating $\mathrm{Pu}$ from weapons or civilian stockpiles.

- Cost cutting: Increases in uranium spot prices and the fear of resource depletion prompted countries to investigate the use of thorium to reduce uranium ore and enrichment requirements in their nuclear fuel programmes.

While consideration of thorium for commercial use is still an academic exercise (IAEA, 2002, 2003, 2005), recent headway has been made by India and China (IThEO, 2015). However, these advances examine fuel mixes of either Th-U or Th-U-Pu. The natural progression is to consider pure Th- $\mathrm{Pu}$ mixes, which have better $\mathrm{Pu}$ incineration rates. Thus, studies on homogeneous $\mathrm{Th}-\mathrm{Pu}$ fuel (without enriched or natural uranium) specifically in PWRs include:

- Lattice calculations: Galperin (1995), Puill (1999), Weaver and Herring (2004), Shwageraus et al. (2004), Dziadosz et al. (2004), Björk and Fhager (2009) and Herman (2009).

- Full-core calculations: Galperin and Raizes (1997), Lombardi et al. (1999), Joo and Kim (2000), Fridman and Kliem (2011), Trellue et al. (2011), Tsige-Tamirat (2011) and Björk et al. (2013).

These investigations compared the performance of different fuel mixes, e.g. Th-Pu/Th-Pu$\mathrm{U} /$ weapons-grade/reactor-grade plutonium, quantified the materials attractiveness of the $\mathrm{Pu}$ product for use in weapons, analysed the fuel and potential SiC cladding at high burnup, and detailed the effects of hydrogen-to-heavy-metal $(\mathrm{H} / \mathrm{HM})$ ratio on $\mathrm{Pu}$ incineration.

The main observations concerning the fuel's behaviour are its reduced reactivity worth and delayed neutron yields which necessitate modification of reactivity control materials (e.g. use of boron enriched in ${ }^{10} \mathrm{~B}$ ), as well as more detailed transient analysis to confirm safe operation. As expected, the Th-Pu mix is found to yield substantially higher rates of $\mathrm{Pu}$ incineration compared to mixtures containing ${ }^{235} \mathrm{U} /{ }^{238} \mathrm{U}$.

Note that in this study we consider a pure Th-Pu fuel mix, without any natural uranium denaturing. Denaturing is the process of adding a certain amount of natural uranium to fissile ${ }^{233} \mathrm{U}$ or ${ }^{235} \mathrm{U}$ in the fuel to inhibit weapons proliferation. As observed by Shwageraus 
et al. (2004) based on ${ }^{233} \mathrm{U}$ threshold limits proposed by Forsberg et al. (1999), there is a degradation in the efficiency of $\mathrm{Pu}$ destruction when the fuel is denatured. The repercussions of denaturing on our conclusions here will be analysed in future work.

\subsection{Moderator temperature coefficient}

The MTC is defined as the change in reactivity per degree change in moderator temperature. Changes in the moderator temperature subsequently insert positive or negative reactivity into the core. A negative MTC at hot full power is a mandatory requirement in all western countries operating PWRs. Thus, the MTC is tracked to ensure safe reactor operation. In a Th-Pu fuel mix, increasing the $\mathrm{Pu}$ content eventually causes the MTC to become positive.

There are 5 main elements that have an effect on MTC (Martin, 2013):

- Leakage: For a fixed core pressure, an increase in temperature necessarily means a decrease in moderator density. This results in fewer collisions between fast neutrons and the hydrogen nuclei of the moderator, resulting in fewer neutrons slowing down or thermalising. Absorption cross-sections get smaller with the consequent harder neutron spectrum. This increases the mean free path of neutrons, and a larger proportion are therefore lost via leakage, causing a reduction in the effective multiplication factor $\left(k_{\text {eff }}\right)$.

- Thermal and resonance absorption: A decrease in moderator density also reduces the number of neutrons absorbed in fissile material in the thermal range (especially in $\mathrm{Pu}$ fuel) creating a negative reactivity effect - a decrease in $k_{\text {eff }}$. However, depending on the nuclide mix, an increase in absorption in the epithermal-fast energy range might be either parasitic or contribute to fission.

- Hydrogen absorption: A moderator density decrease further reduces the number of neutrons lost to absorption by hydrogen in the coolant, creating a positive reactivity effect - an increase in $k_{\text {eff }}$.

- Boron absorption: If the reactivity of the core is controlled using soluble boron, then a decrease in coolant density also means that the amount of soluble boron in the reactor decreases, as some of it is forced out of the core, resulting in a decrease in neutron absorption in boron - an increase in $k_{\text {eff }}$.

- Burnable poison absorption: The shift of the neutron spectrum to higher energies generally causes a decrease in absorption in BPs, thus inserting positive reactivity into the core.

These effects all contribute to the overall MTC. Traditionally, the biggest effect on the MTC is due to the soluble boron. If critical boron concentration (CBC) is high, then a slight increase in temperature can cause a larger positive reactivity insertion. This could cause the net value of the MTC to be positive. Hence the use of BPs for overall reactivity control (rather than local power peaking reduction) is often in order to decrease the CBC 
requirement, rather than directly to improve the MTC. However, the effectiveness of this depends on the fuel and BP used where, in some cases, a judicious choice of BP can, in fact, directly contribute to improving MTC without changing CBC.

\section{Methodology}

\subsection{Model set-up}

The reactor model was based on a standard Westinghouse 3411 MWth 4-loop PWR with 193 fuel assemblies. The homogeneously mixed Th-Pu fuel used in this work contains 20 wt\% $\mathrm{Pu}$, which is roughly the limit beyond which the full-core MTC becomes prohibitively positive. The reactor-grade $\mathrm{Pu}$ isotope vector of $\mathrm{PWR}$ spent fuel with a burnup of 33 GWd/MTU (IAEA, 2003) is given in Table 1. The fuel thermal conductivity for a Th-Pu mix is modelled from (Cozzo et al., 2011). The densities are taken to be $95 \%$ of theoretical for $\mathrm{PuO}_{2}$ and $\mathrm{ThO}_{2}-11.5 \mathrm{~g} / \mathrm{cc}$ and $10 \mathrm{~g} / \mathrm{cc}$ respectively. The reduced boron worth necessitated the use of enriched soluble boron $\left(90\right.$ at $\left.\%{ }^{10} \mathrm{~B}\right)$ for this fuel.

As the reactor follows a 3-batch loading scheme, and the $\mathrm{Pu}$ content is relatively high at $20 \mathrm{wt} \%$, the discharge burnup of the fuel after 3 cycles can reach $130 \mathrm{GWd} / \mathrm{MT}$. However, note that for the purpose of this study, we assume that suitable materials and technology that can withstand prolonged cycles and high burnups will be available for use in the future (Herman, 2009; Shwageraus and Feinroth, 2011; Andrews et al., 2014; Sukjai and Kazimi, 2015). Hence discharge burnup is not, as with current commercial reactors, a constraint or limiting factor; instead, it is an objective. This is due to the fact that the $\mathrm{Pu}$ content in the fuel decreases monotonically with burnup, i.e. a deeper burn increases $\mathrm{Pu}$ incineration.

Lattice calculations were performed using WIMS 10, a deterministic reactor physics code (Newton et al. 2008). A 172-group calculation with geometric approximations was first performed using the collision probability method to generate 47 -group cross-sections. The geometric approximations refer to a solution of the slowing down equation in a simplified unit cell geometry with a small number of regions (fuel, cladding, moderator) coupled through collision probabilities, which is a standard computational sequence. A few-group solution in detailed geometry was then performed using the method of characteristics.

Full-core calculations were carried out using PANTHER (Hutt et al., 1991; Parks and Knight, 1995), a general-purpose whole reactor code that solves the multi-group neutron diffusion equation with coupled thermal and poison feedback. PANTHER can model the effects of fission product poisoning due to the presence of ${ }^{135} \mathrm{Xe}$ and ${ }^{149} \mathrm{Sm}$ by solving the appropriate decay chain equations to give the number densities of the poison isotopes. Therefore it provides the option of using the nominal values produced when the nuclear parameters were generated at the lattice level calculation stage, or calculating its own Xe/Sm number densities which feeds back a change in the mesh constants (cross-sections). Core calculations were carried out using 2-energy-group cross-sections.

\subsection{Analysis of contribution to $M T C$}

To understand the factors that govern the behaviour of MTC in our Th-Pu fuel, we break down the contributions to the MTC by isotope and then by energy group. The method used 


\begin{tabular}{lccccc}
\hline Isotope & ${ }^{238} \mathbf{P u}$ & ${ }^{239} \mathbf{P u}$ & ${ }^{240} \mathbf{P u}$ & ${ }^{241} \mathbf{P u}$ & ${ }^{242} \mathbf{P u}$ \\
\hline$\%$ & 1.8110 & 59.1380 & 22.9577 & 12.1313 & 3.9620 \\
\hline
\end{tabular}

Table 1. Plutonium isotope vector.

$k_{\infty}$ can be written as

$$
k_{\infty}=\eta_{1} \tilde{f}_{1}+\eta_{2} \tilde{f}_{2}+\cdots,
$$

where

$\eta_{j}=$ the total number of fission neutrons emitted per neutron absorbed in component $j$,

$\tilde{f}_{j}=$ the fraction of neutrons absorbed in component $j$ out of the total number of neutrons absorbed in all the system components $i$, which is a definition that differs slightly from the standard one for $f$.

In the definition above, "component" refers to any division required, e.g. by isotope, energy group, etc. For a change in moderator temperature, $\triangle T$, the MTC by component 
can now be expressed as follows:

$$
\begin{aligned}
M T C_{T} & =\frac{k_{\infty}^{p}-k_{\infty}^{n}}{k_{\infty}^{p} \cdot k_{\infty}^{n}} \frac{1}{\triangle T} \\
& =\frac{1}{\triangle T} \frac{\left(\left.\eta_{1} \tilde{f}_{1}\right|_{p}-\left.\eta_{1} \tilde{f}_{1}\right|_{n}\right)+\left(\left.\eta_{2} \tilde{f}_{2}\right|_{p}-\left.\eta_{2} \tilde{f}_{2}\right|_{n}\right)+\cdots}{k_{\infty}^{p} \cdot k_{\infty}^{n}}
\end{aligned}
$$

and the subscripts and superscripts $n$ and $p$ denote for the nominal and perturbed conditions, respectively.

\section{Results}

\subsection{Contributing effects to $M T C$}

As the moderator increases in temperature, it becomes less dense and slows down neutrons less efficiently, thus "hardening" the neutron spectrum or changing the energy distribution of neutrons in the reactor. Fig. 1 plots the normalised neutron flux spectrum for a fuel assembly containing homogeneously mixed $20 \mathrm{wt} \% \mathrm{Pu}$ with Th (Th80Pu20 fuel), at its (a) nominal condition (moderator density and temperature of $0.7119 \mathrm{~g} / \mathrm{cc}$ and $580 \mathrm{~K}$ ), (b) perturbed condition $(0.611 \mathrm{~g} / \mathrm{cc}$ and $600 \mathrm{~K})$, and (c) the difference between these two spectra (perturbed - nominal). It is clear that there is a decrease of thermal neutrons and an increase of epithermal neutrons above $100 \mathrm{eV}$.

Using the method described in the Sect. 2.2, we analyse the MTC contribution by isotope for representative fresh $(0.1 \mathrm{GWd} / \mathrm{MT})$ and twice-burnt fuel $(85 \mathrm{GWd} / \mathrm{MT})$ under average core boron concentrations of $1600 \mathrm{ppm}$. This is done by perturbing the moderator temperature and calculating the MTC contribution to the total value of fuel assembly MTC of each isotope. From Fig. 2, we see that the key nuclides that play a significant role are ${ }^{239} \mathrm{Pu}$, ${ }^{241} \mathrm{Pu}$ and ${ }^{233} \mathrm{U}$. To understand this better, we break this down further to MTC contribution over energy range for each isotope - Fig. 3. We see that for both fresh and depleted fuel, the main contribution to positive MTC is an increased fissioning in the epithermal range of $\sim 100 \mathrm{eV}$ to $10 \mathrm{keV}$ for the key nuclides, i.e. ${ }^{239} \mathrm{Pu},{ }^{241} \mathrm{Pu}$ and ${ }^{233} \mathrm{U}$. However, note that, for ${ }^{239} \mathrm{Pu}$, the large negative contribution in the thermal range below $1 \mathrm{eV}$ offsets the positive contribution giving a net negative contribution to MTC at $85 \mathrm{GWd} / \mathrm{MT}$ (Fig. 2).

These changes in MTC can be attributed to the changes in the parameter $\eta$ - the number of neutrons emitted by fission per neutron absorption in the fuel, plotted for ${ }^{239} \mathrm{Pu}$ in Fig. $3 \mathrm{a}$ and ${ }^{233} \mathrm{U}$ in Fig. 3b. An interesting point to note is that while ${ }^{233} \mathrm{U}$ is a thermal absorber (Fig. 4), thus contributing to negative MTC when the spectrum shifts to higher energies, it still contributes quite significantly to the positive MTC of the fuel at high burnup. As mentioned, it is an increase in fission, as shown by an increase in the parameter $\eta$ in the epithermal range, that causes this.

What this analysis indicates is that the MTC of our Th-Pu fuel is predominantly affected by fissioning in the epithermal energy range. This means that without changing standard assembly configurations, a change in fuel type, i.e. U compared to Th-Pu fuel, has effectively changed the behaviour of the assembly from most fissions being caused by thermal neutrons to a mostly epithermal-fast fission dominated fuel. 


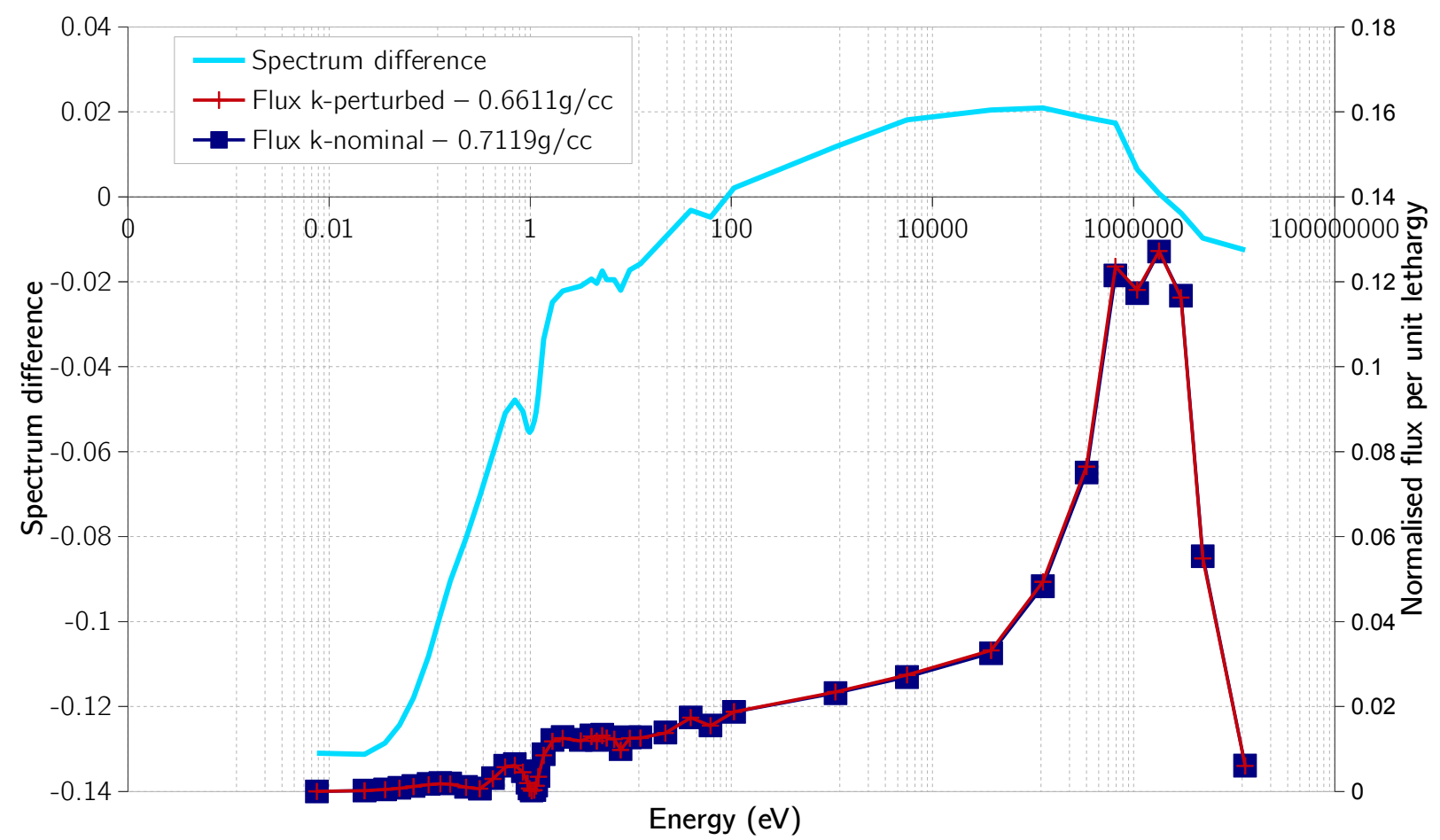

Fig. 1. Spectrum difference of the flux change from nominal moderator density of $0.7119 \mathrm{~g} / \mathrm{cc}$ to an increase in temperature with a density of $0.611 \mathrm{~g} / \mathrm{cc}$.

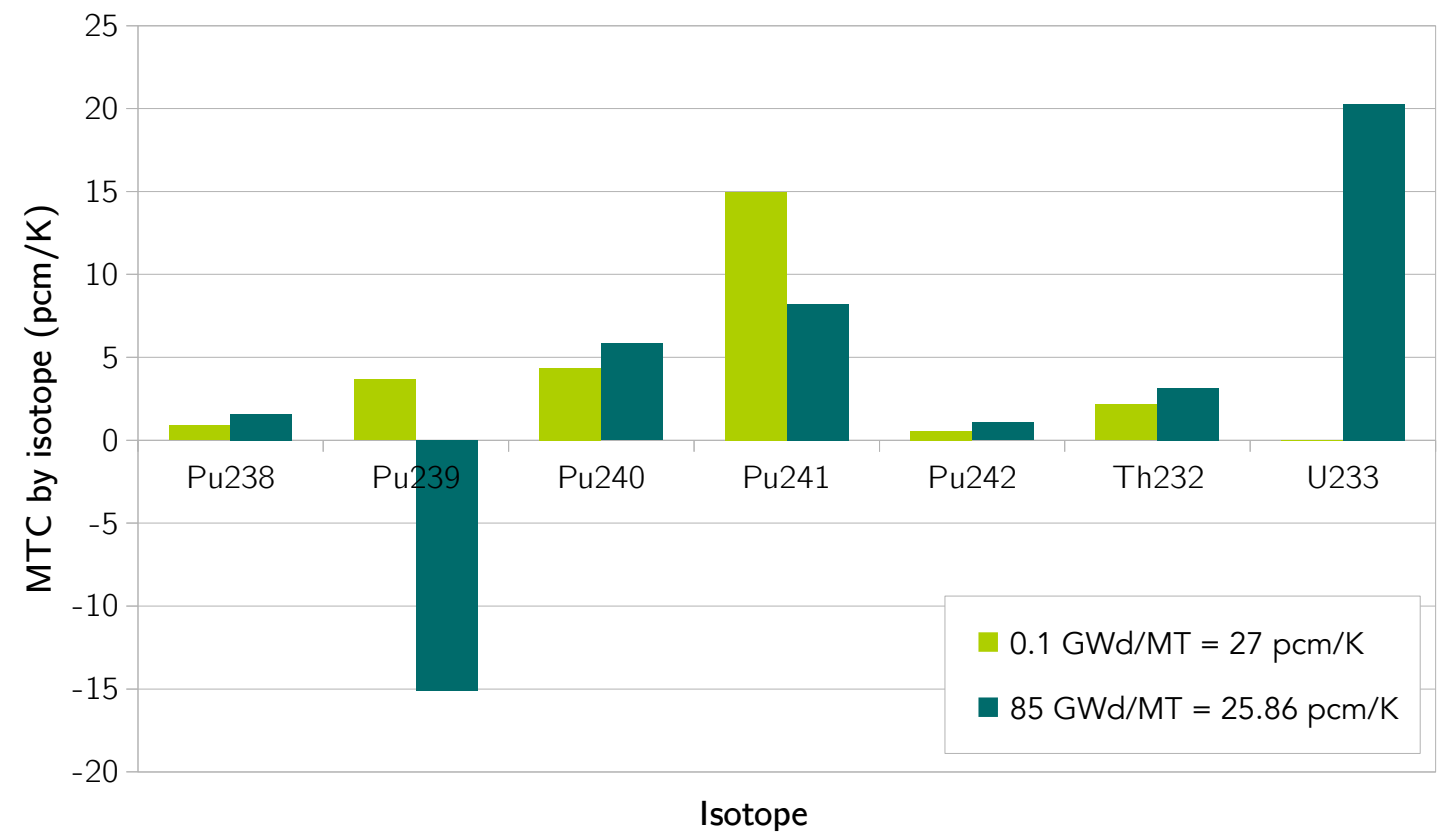

Fig. 2. MTC contribution by isotope for fresh and twice-burnt fuel at core average boron (1600 ppm). $\mathrm{MTC}$ at $0.1 \mathrm{GWd} / \mathrm{MT}=26.59 \mathrm{pcm} / \mathrm{K}$ and $85 \mathrm{GWd} / \mathrm{MT}=25.86 \mathrm{pcm} / \mathrm{K}$. 


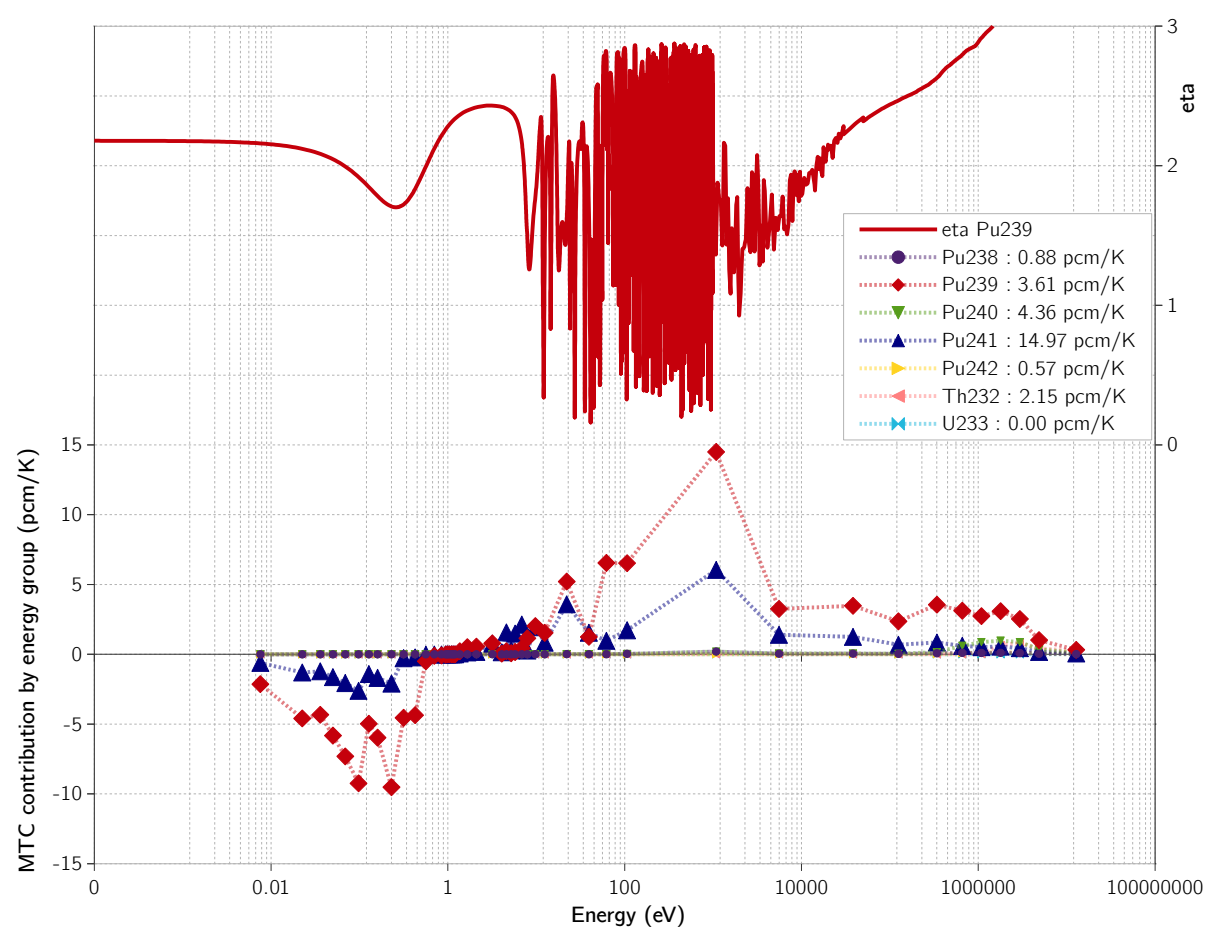

(a) $0.1 \mathrm{GWd} / \mathrm{MT}, \mathrm{MTC}=26.587 \mathrm{pcm} / \mathrm{K}$

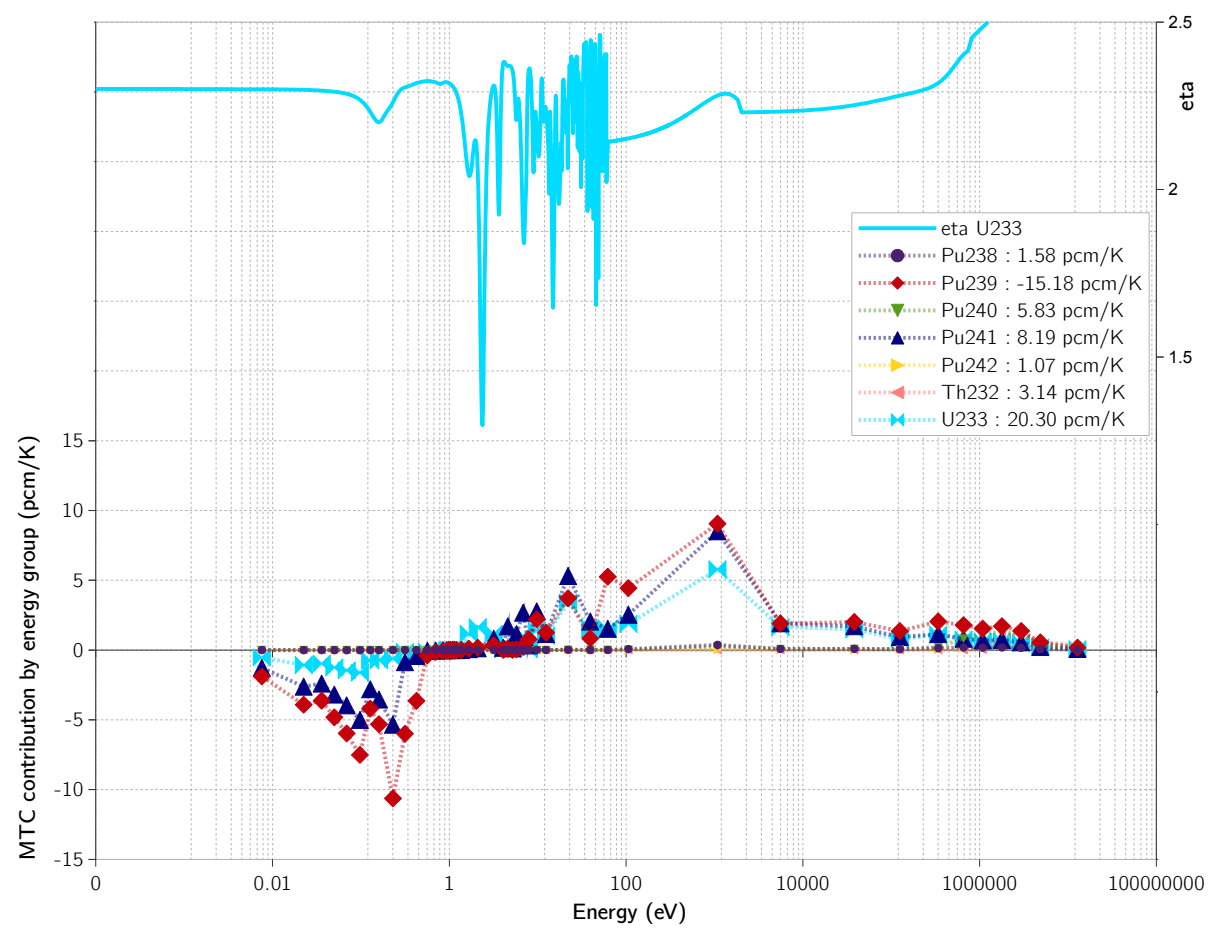

(b) $85 \mathrm{GWd} / \mathrm{MT}, \mathrm{MTC}=25.857 \mathrm{pcm} / \mathrm{K}$

Fig. 3. Breakdown of MTC by energy group for each isotope for (a) fresh and (b) twice-burnt fuel at core average boron $(1600 \mathrm{ppm})$. Second (upper) plots show the parameter $\eta$ for key nuclides $-{ }^{241} \mathrm{Pu}$ and ${ }^{233} \mathrm{U}$. 


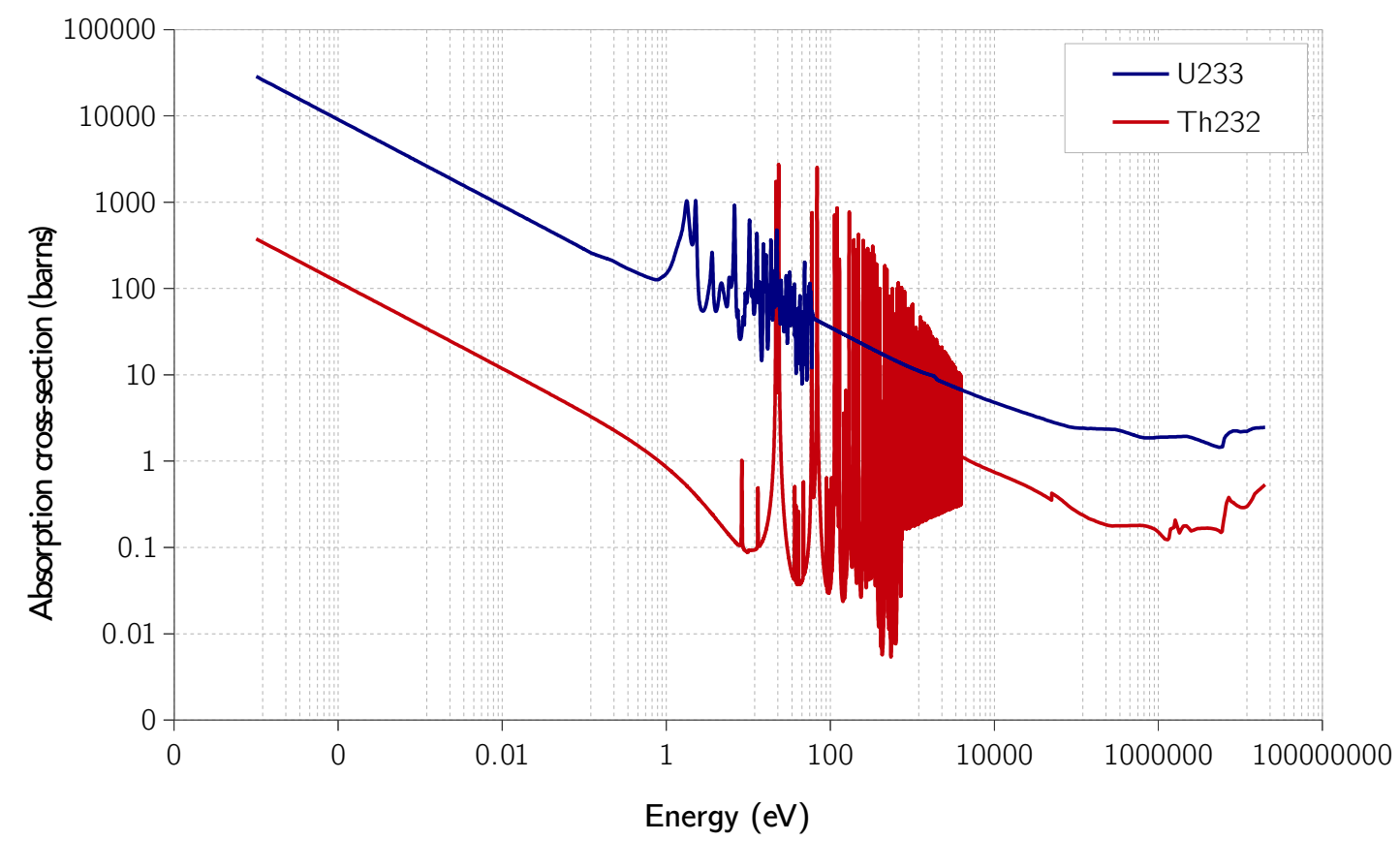

Fig. 4. ${ }^{232} \mathrm{Th}$ and ${ }^{233} \mathrm{U}$ absorption cross-sections show that ${ }^{232} \mathrm{Th}$ is an epithermal absorber compared to ${ }^{233} \mathrm{U}$, which is more of a thermal absorber.

We must take this into consideration when choosing a suitable burnable poison that will help improve the MTC of the fuel.

\subsection{Burnable poison selection}

Burnable poisons are materials that have very large absorption cross-sections that deplete with neutron capture. The daughter products produced as a result of this would ideally have negligible absorption cross-sections so as not to cause added reactivity hold-down beyond the initial intended design.

There are three variables that determine the behaviour of a BP in an assembly:

- Number of pins: This determines the reactivity hold-down, as the amount of exposure the BPs have to neutrons is proportional to the number of pins.

- BP enrichment/loading: This determines how long the BPs have an effect on the fuel.

- BP nuclide/isotope: The type of nuclide determines the magnitude of the absorption cross-section. Large absorption cross-sections (e.g. ${ }^{157} \mathrm{Gd}$ ) imply that the BPs will have a very large initial effect (i.e. large reactivity hold-down), but then quickly burnt out.

The effect of these variables on BP behaviour will differ depending on the material used. For example, due to the strong self-shielding of gadolinium, the exact method of loading, i.e. number of pins and enrichment, will affect the reactivity curve, but, in contrast, for 
boron, poison distribution is not as important. The objective then is to balance these three factors such that the BPs burn out by the end of the first cycle, so as not to incur a burnup penalty that shortens the fuel's life.

\subsubsection{Lattice level calculations}

We will first examine standard Wet Annular Burnable Absorbers (WABAs) and Integral Fuel Burnable Absorbers (IFBAs). WABAs are burnable absorber rods that comprise of thin-walled $\mathrm{Al}_{2} \mathrm{O}_{3}-\mathrm{B}_{4} \mathrm{C}$ annular pellets contained within two concentric and sealed Zircaloytubes, so as to allow the flow of coolant inside and outside of the tube (Radford et al., 1982), and are placed in guide tube positions. This means that they are usually removed from the assembly after the first cycle, so as to allow for the inevitable reshuffling of the assembly to control rod positions in the core. IFBAs, on the other hand, are standard fuel pellets with a thin coating of $\mathrm{ZrB}_{2}$ on the outer surface (Simmons et al., 1987).

For this lattice level calculation, a reference point for cycle burnup was determined using the Linear Reactivity Model (LRM) (Driscoll et al., 1991) and was calculated using the reactivity of the fuel assemblies without BPs. This cycle burnup reference point is used in analysing when BPs should ideally burn out, and consequently used in finding the average critical boron that is set across all fuels when generating cross-sections.

Soluble boron concentration is limited by water chemistry considerations and, to some extent, by the restrictions on MTC. Therefore, BPs should be able to compensate for the remaining excess reactivity. With a rough estimate of soluble boron reactivity worth, it is possible to estimate the BP requirements from the lattice calculations and the LRM. These rough estimates allowed us to rule out some of the BP options that would clearly be unable to provide the necessary amount of excess reactivity compensation.

Fig. 5 shows the effect of variation in ${ }^{10} \mathrm{~B}$ enrichment for both $\mathrm{BP}$ types. Note that at this first stage of comparing WABAs and IFBAs, we are mainly interested in their behaviour in the first cycle. Therefore to simplify modelling, the WABAs are left in the assembly throughout the assembly life - hence the reactivity hold-down after the first cycle. Nevertheless, they do not give sufficient reactivity hold-down in the first cycle.

An IFBA with $0.001 \mathrm{~cm}$ coating thickness on all the fuel pins with an enrichment of $90 \mathrm{wt} \%{ }^{10} \mathrm{~B}$ performed similarly to WABAs using natural boron. Therefore it was deemed necessary to increase the thickness of the IFBA coating to $0.004 \mathrm{~cm}$ (Kozlowski and Downar, 2007; Ellis, 2000), which then gave better reactivity hold-down, though it still burnt through the second cycle. The IFBA with enrichment of $50 \mathrm{wt} \%{ }^{10} \mathrm{~B}$ appeared to be the best contender.

We then considered homogeneously mixed BPs placed in all the pins in the assembly. The nuclides examined were commercially available BPs, including gadolinium, erbium, europium and hafnium. Fig. 6 shows the total cross-sections of the main absorbing isotope for each nuclide. Notice that all the isotopes behave in a relatively similar way in the region between $\sim 100 \mathrm{eV}$ and $10 \mathrm{keV}$ with the exception of ${ }^{177} \mathrm{Hf}$, which displays particularly strong resonance absorption. Based on the discussion of epithermal-fast fissioning in the previous section, this behaviour will be valuable.

However, we are still bound by operational constraints, i.e. burnup, by which the ideal 


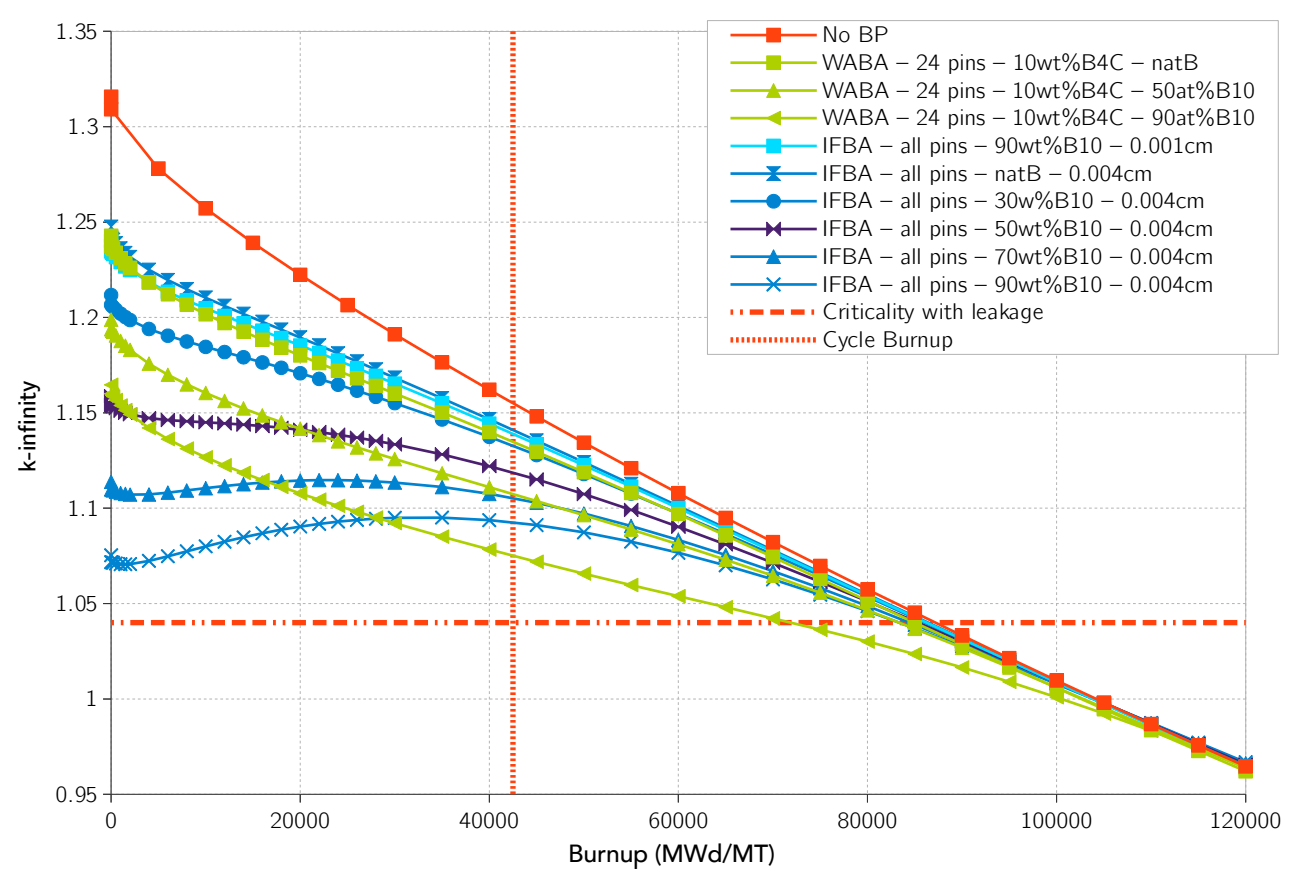

Fig. 5. $k_{\infty}$ versus burnup for WABA and IFBA options for Th80Pu20 fuel.

BP should burn out by the end of the first cycle, and, more importantly, must cause the least amount of burnup penalty. To get a feel for the BP behaviour, we plot the $k_{\infty}$ versus burnup variation for $1 \mathrm{wt} \%$ of the natural composition of each BP in Fig. 7a. This shows Gd to have the most promise. We then plot the variation for $1 \mathrm{wt} \%$ of the crucial absorbing isotopes for each nuclide in Fig. 7b, and then adjust the wt\% of each isotope to ideally burn out after the first cycle in Fig. $7 \mathrm{c}$. ${ }^{164} \mathrm{Dy},{ }^{167} \mathrm{Er},{ }^{151} \mathrm{Eu}$ and ${ }^{177} \mathrm{Hf}$ give relatively little initial reactivity hold-down.

${ }^{157} \mathrm{Gd}$ caused too much hold-down because it was placed in all the pins. While a more optimised configuration (i.e. reducing number of pins and enrichment) could be found, for the purpose of this basic study, a uniform placement of BPs in all the fuel pins was adopted for consistency of comparison with the other BPs. Furthermore, the focus on total Gd absorption is reasonable as our main concerns were the reactivity hold-down and effect on MTC.

More promisingly, $0.2 \mathrm{wt} \%$ Gd155 gives a reasonable hold-down in the first cycle and minimal burnup penalty.

Additionally, note that in Fig. 7b, the reactivity for the homogeneously mixed $\mathrm{BP}$ of $1 \mathrm{wt} \%{ }^{157} \mathrm{Gd}$ is strongly suppressed initially, and burns out quite quickly. At the end of the first cycle, however, its reactivity is higher than the case with no BP. This is a spectral history effect of ${ }^{233} \mathrm{U}$. As ${ }^{157} \mathrm{Gd}$ is a strong thermal absorber, it hardens the neutron spectrum. However, since ${ }^{232} \mathrm{Th}$ is an epithermal absorber (Fig. 4), this encourages breeding of ${ }^{233} \mathrm{U}$. When ${ }^{157} \mathrm{Gd}$ proceeds to burn out at the end of the cycle, the spectrum softens, creating an ideal environment for the fissioning of ${ }^{233} \mathrm{U}$, and thus the increased reactivity seen in Fig. $7 \mathrm{~b}$. 


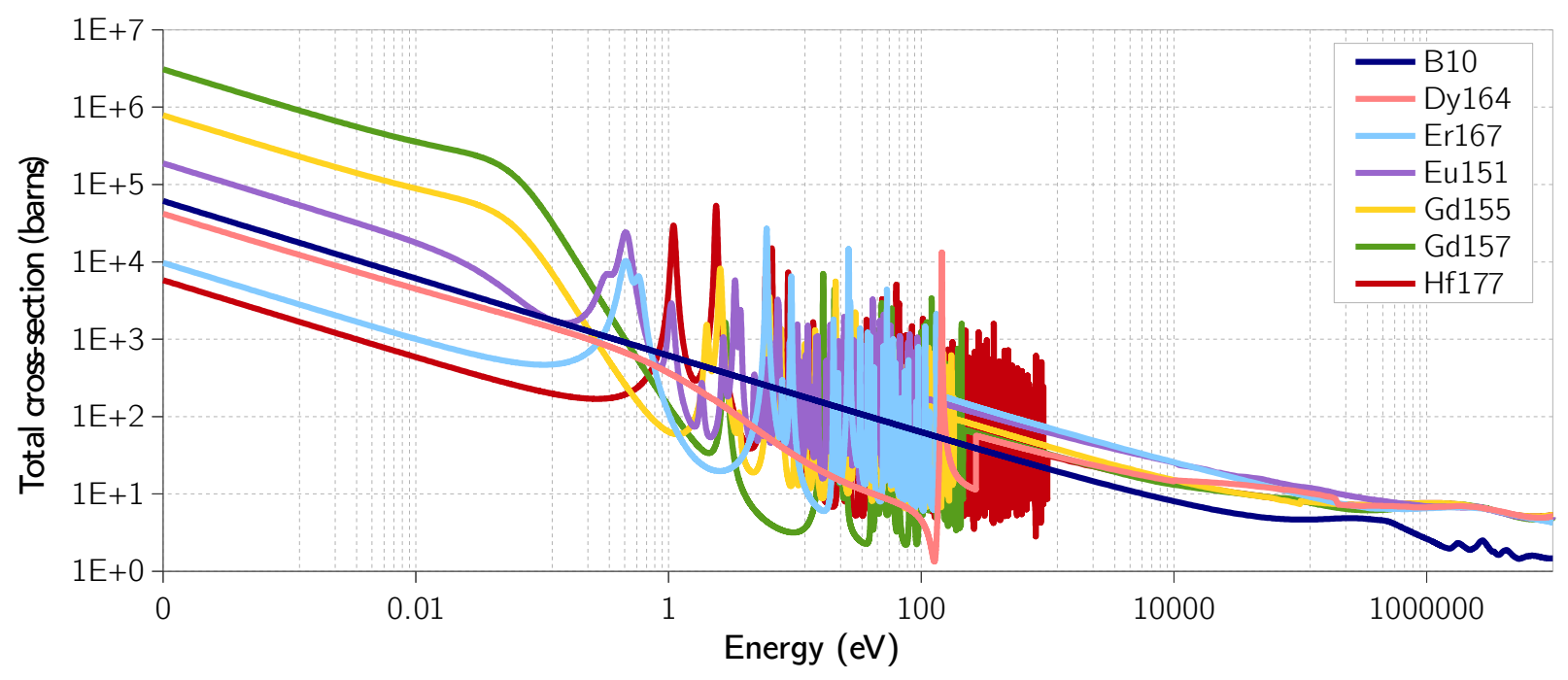

Fig. 6. Total cross-sections of candidate burnable poisons.

From the options discussed so far, Fig. 8 shows the three candidate configurations for BPs to be placed in all the pins of the assembly that were considered the most promising:

1. IFBA of thickness $0.004 \mathrm{~cm}$ containing $50 \mathrm{wt} \%{ }^{10} \mathrm{~B}$

2. Homogeneously mixed $0.2 \mathrm{wt} \%{ }^{155} \mathrm{Gd}$

3. Homogeneously mixed $0.2 \mathrm{wt} \%{ }^{177} \mathrm{Hf}$

The first two were chosen due to their reasonable reactivity hold-down in the first cycle. In contrast, ${ }^{177} \mathrm{Hf}$ was chosen to test the previously mentioned hypothesis that MTC is affected by epithermal-fast fission, since it offers more resonance absorption in the relevant energy range than the other $\mathrm{BP}$ options.

\subsection{Full-core evaluation of BP fuel}

It is usually thought that positive MTC in PWRs is caused by the high concentrations of soluble boron required to maintain criticality in highly enriched fuel. But we show here that for Th-Pu fuel, CBC is only loosely correlated with MTC, i.e. reducing boron concentration by using BPs has negligible effect on MTC.

\subsubsection{BPs in full core}

The main contributor to a positive MTC is increased fissioning in the epithermal-fast region. As we will see, a decrease in CBC is not essential to help attain a negative MTC; instead leakage and a reduction in epithermal-fast fissioning are more important.

For standard uranium cores, it is well-understood that for an increase in moderator temperature, boron content in the core will be reduced and cause an insertion of positive reactivity. Thus, to mitigate this detrimental effect on MTC from the soluble boron, the use of BPs helps decrease the reactivity of the fuel, and hence the $\mathrm{CBC}$ required. 


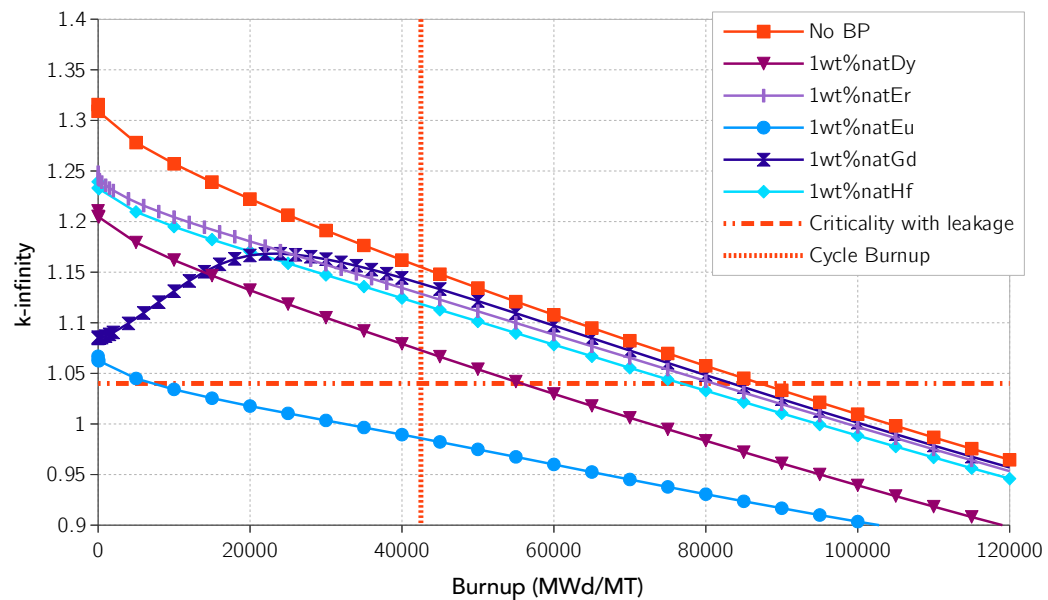

(a) Natural BPs

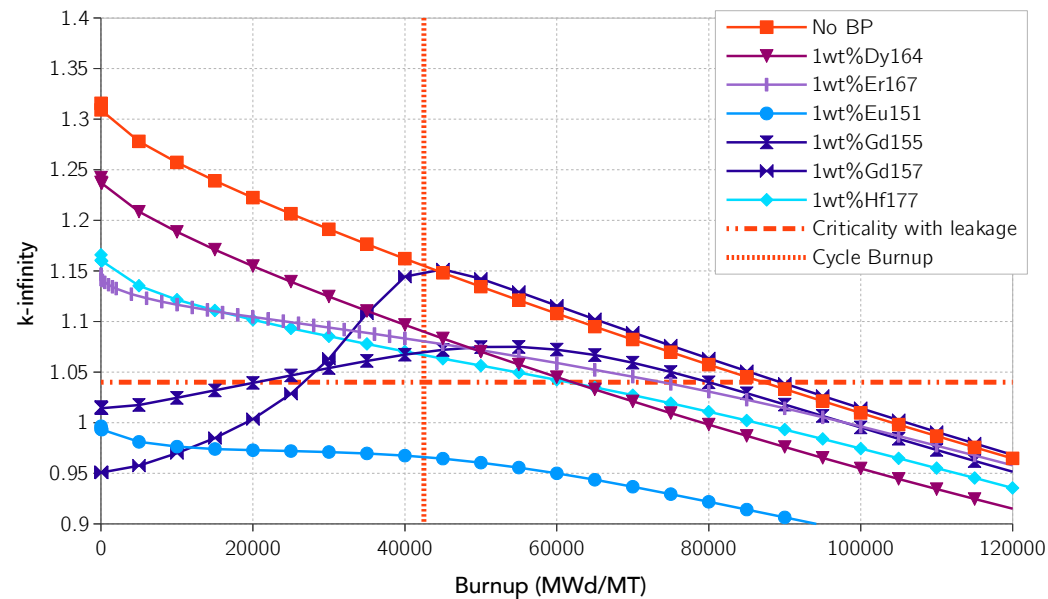

(b) Isotope BPs

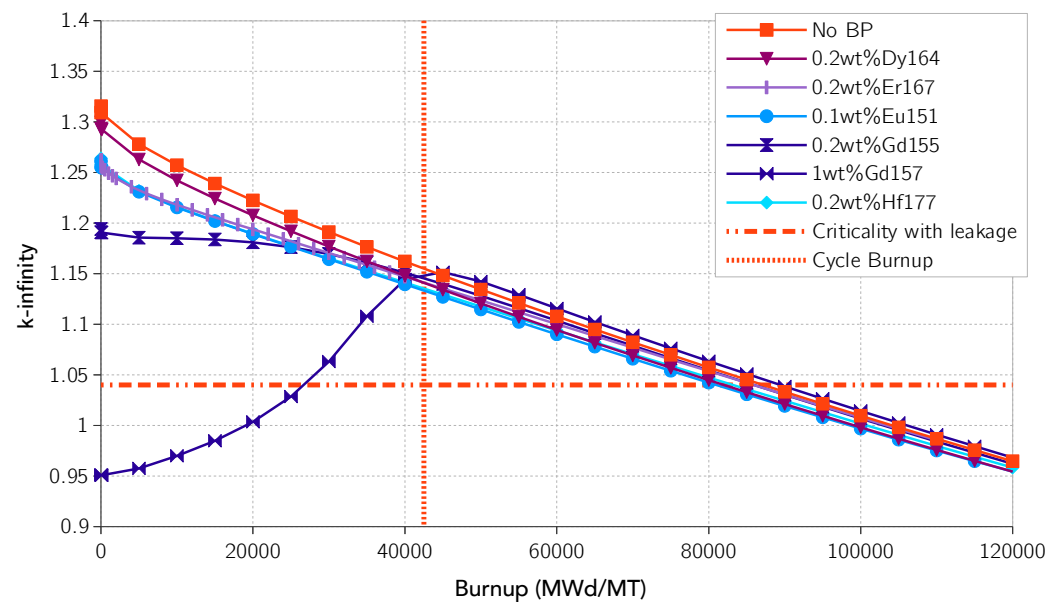

(c) Adjusted isotope BPs

Fig. 7. $k_{\infty}$ versus burnup for (a) natural and (b) and (c) particular isotope BPs. 


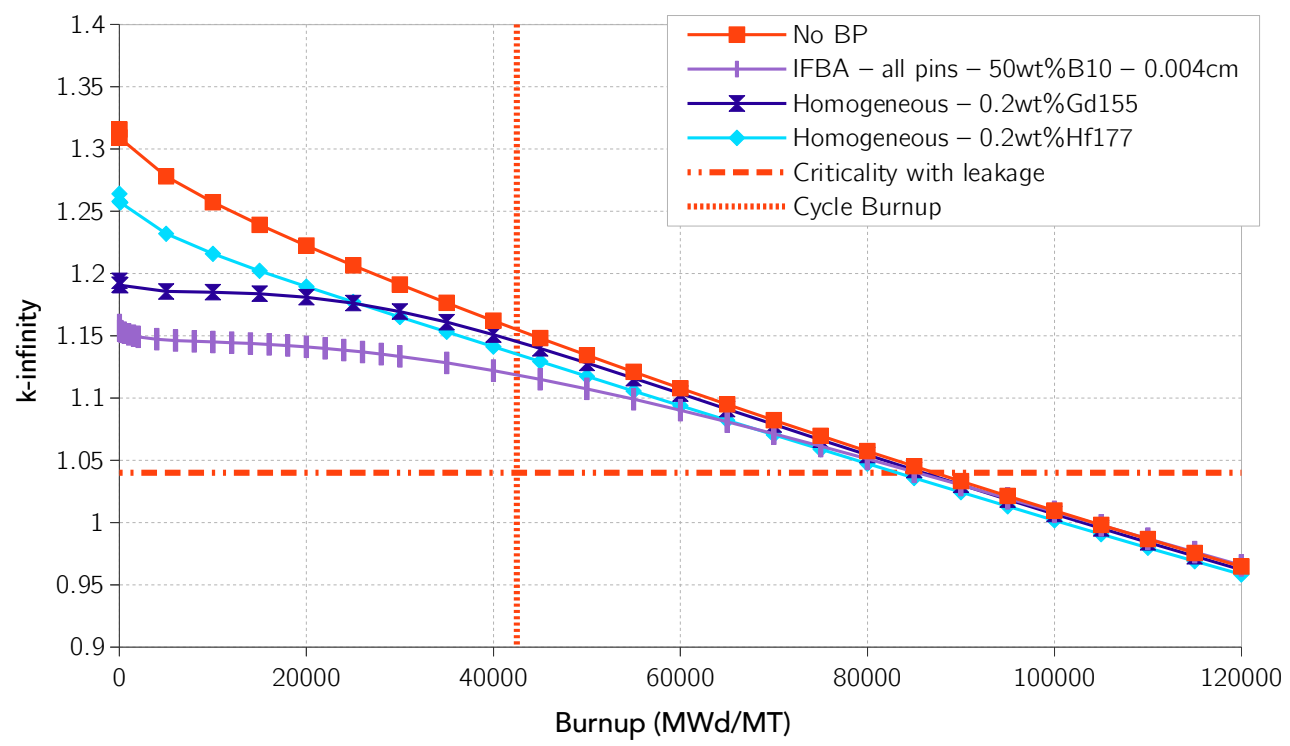

Fig. 8. Final BP candidates considered.

For our full-core study, we analyse 3 commonly used loading patterns (LPs) shown in Fig. 9. LP1 is a standard Out-In-In pattern that has fresh fuel located on the periphery of the core and the once- and twice-burnt fuel checkerboarded in the interior. LP2 is a Ring-of-Fire configuration where twice-burnt fuel is placed on the periphery, fresh fuel is placed one assembly in from the periphery, and once-burnt fuel is placed in the centre of the core. Finally, LP3, an In-Out-In design, checkerboards fresh and twice-burnt fuel in the centre of the core and places once-burnt fuel on the periphery.

Fig. 8 showed that the ${ }^{177} \mathrm{Hf},{ }^{155} \mathrm{Gd}$ and IFBA designs, in that order, give increasingly large initial reactivity hold-downs. This is reflected in an improvement in RFF for all LPs (Fig. 10a) but, more importantly, a reduction in required CBC for all LPs in the same order, with the IFBA giving the most hold-down and ${ }^{177} \mathrm{Hf}$ the least (Fig. 10b). This behaviour is not necessarily reflected in the MTC, however (Fig. 10c).

First, we note from Fig. 11 (a close-up of the results in Fig. 10c highlighting the different LPs), that BPs do indeed reduce MTC for LP2 and LP3 compared to fuel with no BP, but provide no reduction in MTC when LP1 is used. This indicates that leakage has a much larger effect on MTC than BPs. Thus, the inclusion of BPs in fuel assemblies that are loaded using LP1 does not help improve MTC. However, BPs can help improve MTC if LP2 or LP3 is adopted, where fresh fuel assemblies are loaded in the interior of the core.

The second behaviour to note from the MTC of the different fuels in Fig. 12 (another close-up of Fig. 10c, highlighting different BPs for LP1) is that ${ }^{177} \mathrm{Hf}$, which provided the least initial reactivity hold-down, and consequently the least reduction in $\mathrm{CBC}$, is able to give a lower MTC $(-2.9483 \mathrm{pcm} / \mathrm{K}$ at beginning of cycle $(\mathrm{BOC}))$ than with IFBA $(-0.2786 \mathrm{pcm} / \mathrm{K})$. This confirms our earlier conclusion that epithermal-fast fission above $100 \mathrm{eV}$ has more effect on MTC than CBC, and, from the absorption cross-sections shown in Fig. 6. ${ }^{177} \mathrm{Hf}$ offers more resonance absorption in this particular region than the other BP 

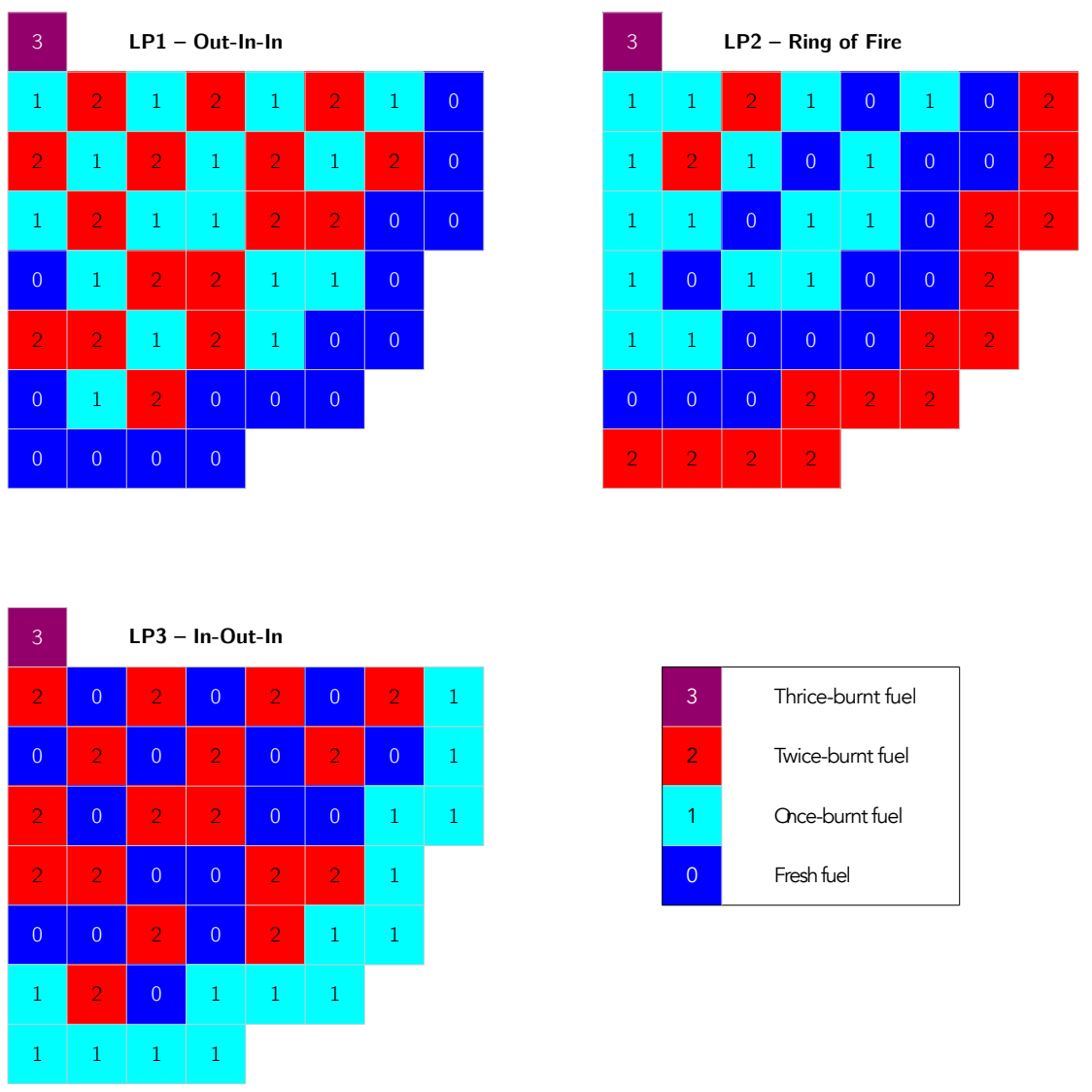

Fig. 9. LPs used in the full-core evaluations. 


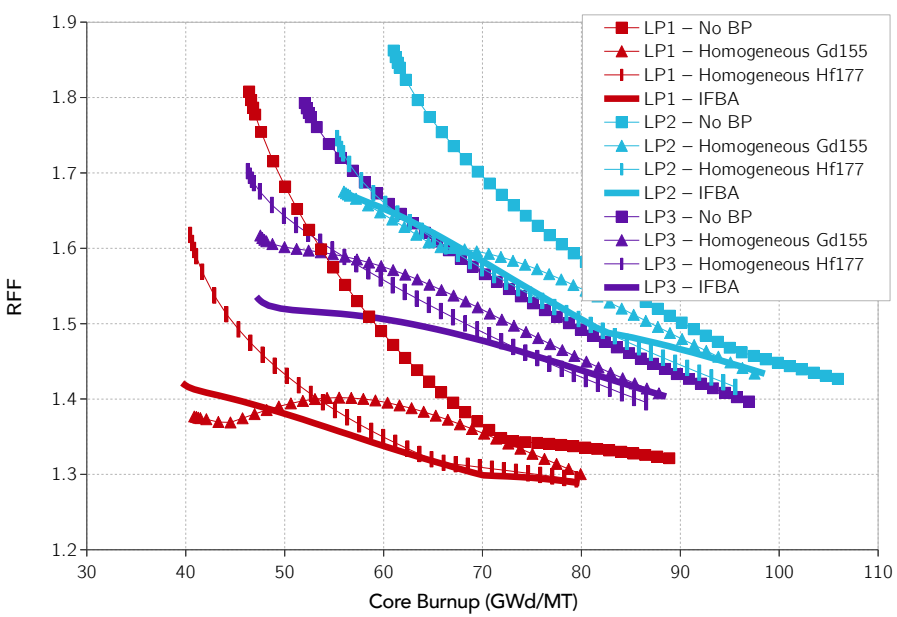

(a) RFF

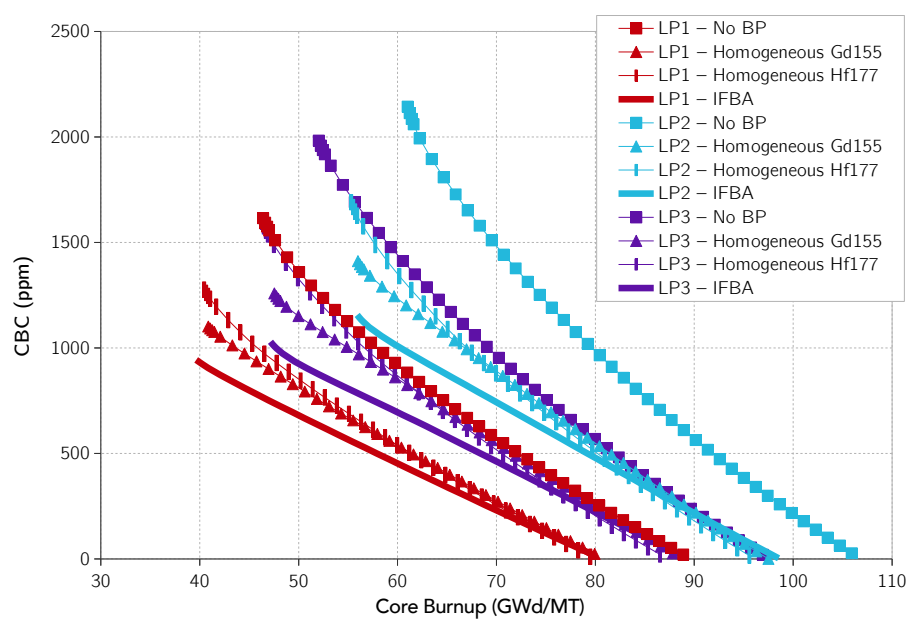

(b) $\mathrm{CBC}$

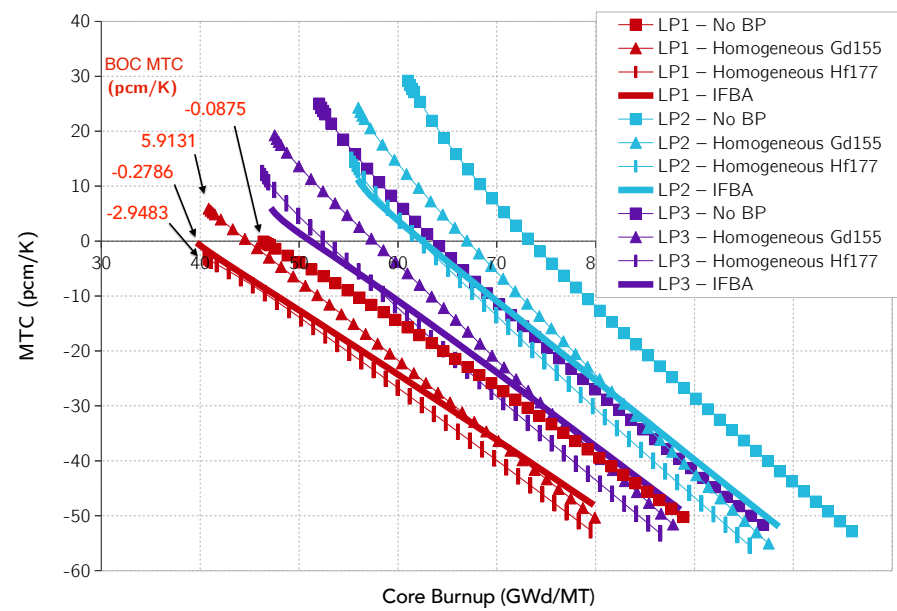

(c) MTC

Fig. 10. Full-core results for (a) RFF, (b) $\mathrm{CBC}$ and (c) MTC. 


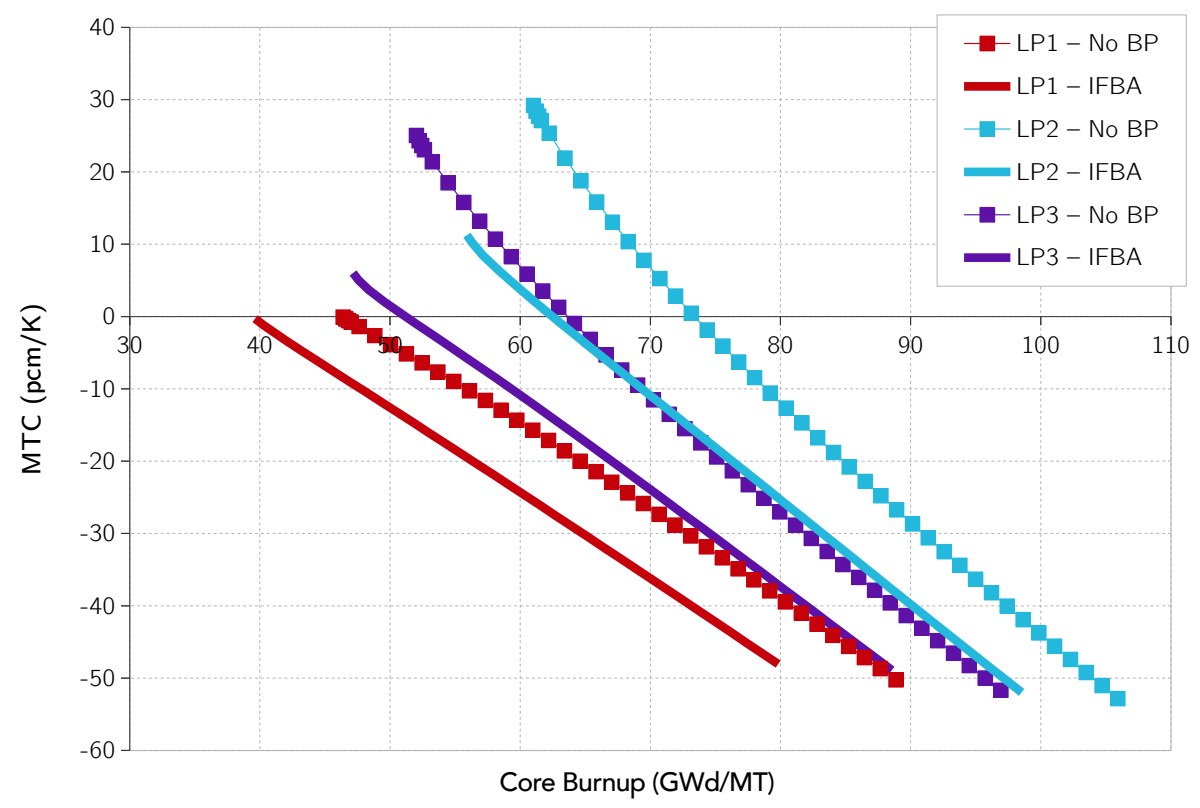

Fig. 11. Effect of IFBA on MTC for different loading patterns.

nuclides.

Conversely, ${ }^{155} \mathrm{Gd}$ deteriorates MTC (5.9131 pcm/K at BOC) compared to the case with no BPs $(-0.0875 \mathrm{pcm} / \mathrm{K})$ despite causing a reduction in CBC. This is due to its much reduced absorption cross-section in the epithermal region (Fig. 6), whereby the shift in spectrum to higher energies results in an insertion of positive reactivity. This reverse in behaviour is only seen when using LP1. As leakage reduces the positive contribution from epithermal-fast fission, the influence of the reduction in ${ }^{155} \mathrm{Gd}$ absorption in the epithermal range becomes more significant.

\section{Conclusions}

To achieve a "deep burn" of $\mathrm{Pu}$ with $\mathrm{Th}-\mathrm{Pu}$ fuel in a PWR, we aim to load the reactor with the highest possible amount of $\mathrm{Pu}$ in order to extend the fuel burnup through ${ }^{233} \mathrm{U}$ breeding and burning, which requires a long time to build up to saturation. However, the amount of $\mathrm{Pu}$ is constrained by:

- High RFF that stems from the large differences in burnup and therefore reactivity between fresh and burnt assemblies.

- Positive MTC, which was originally thought to be primarily caused by the large soluble boron concentrations needed to maintain criticality for fuel with high $\mathrm{Pu}$ content. However, a detailed study of the contributing effects to positive MTC shows that the key factor is, in fact, increased fissioning of ${ }^{239} \mathrm{Pu},{ }^{241} \mathrm{Pu}$ and, with sufficient build-up, ${ }^{233} \mathrm{U}$ in the epithermal-fast energy range. 


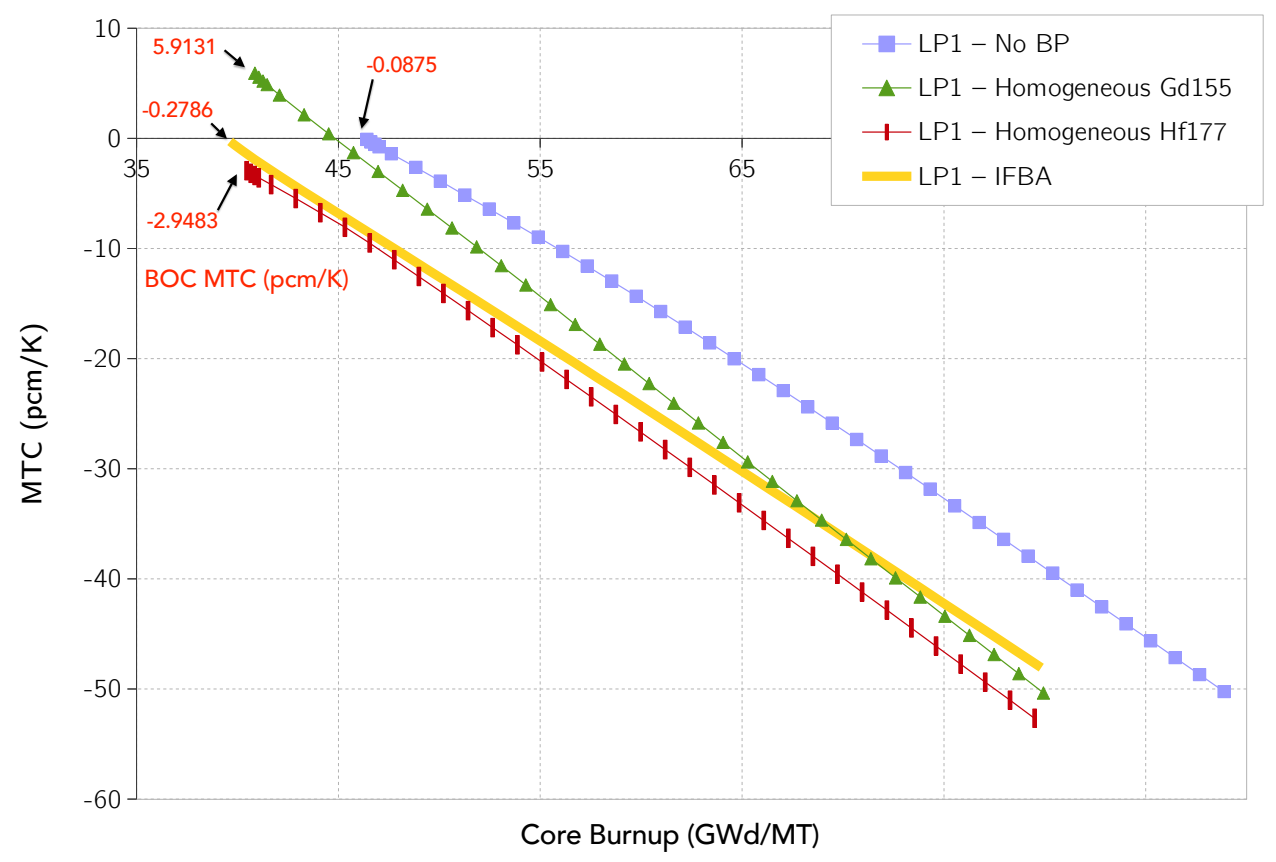

Fig. 12. MTC for different BPs for LP1.

The judicious use of BPs can reduce RFF without much compromise on cycle length. However, depending on the principal poison isotope, the use of BPs has varying effects on MTC.

The results of this investigation into the effects of BPs on MTC in Th-Pu-fuelled PWRs can be summarized as follows:

- The MTC of Th-Pu fuel is affected much more by core leakage than by BPs. For lowleakage cores, where fresh fuel is placed towards the centre of the core, BPs can help lower MTC, but, for high-leakage cores, the use of BPs will only marginally improve MTC, if at all.

- ${ }^{177} \mathrm{Hf}$ provides the least reactivity hold-down, but as the most significant contribution to positive MTC is from increased fissioning in the epithermal-fast energy range, and ${ }^{177} \mathrm{Hf}$ has resonances in this region, it is able to mitigate this effect.

- In contrast, ${ }^{155} \mathrm{Gd}$ can deteriorate MTC as it is a strong thermal absorber. Its absorption cross-section is much smaller in the epithermal region, so a shift in spectrum to higher energies results in an insertion of positive reactivity.

- IFBAs containing $50 \mathrm{wt} \%{ }^{10} \mathrm{~B}$ of $0.004 \mathrm{~cm}$ thickness on all pins performed relatively well for all three parameters of interest - RFF, CBC and MTC.

While high-leakage cores have a stronger effect in mitigating positive MTC, the use of BPs will be important when a low-leakage core is required. 
Having gained an understanding of the specific cause of positive MTC in high Pu content fuel, effective loading patterns and also the characteristics of BPs that can help mitigate a positive MTC, a more comprehensive study should be carried out using more realistic BP designs. This will enable a more feasible design of a high $\mathrm{Pu}$ content reactor where MTC can be better managed.

\section{Acknowledgements}

The first author is grateful for the financial support of Yayasan Tenaga Nasional, Malaysia.

\section{References}

Andrews, N., Pilat, E., Shirvan, K., Kazimi, M.S., 2014. Impact of SiC cladding on plutonium burning in a thorium fueled PWR, in: Proc. ICAPP 2014, Charlotte, NC.

Björk, K.I., Fhager, V., 2009. Comparison of thorium-plutonium fuel and MOX fuel for PWRs, in: Proc. Global 2009, Paris, France.

Björk, K.I., Lau, C.W., Nylén, H., Sandberg, U., 2013. Study of thorium-plutonium fuel for possible operating cycle extension in PWRs. Sci. Technol. Nucl. Install. 2013, 867561.

Broomby, R., 2013. UK's Plutonium Stockpile Dilemma. URL: http://www.bbc.co.uk/news/ uk-21505271.

Cozzo, C., Staicu, D., Somers, J., Fernandez, A., Konings, R.J.M., 2011. Thermal diffusivity and conductivity of thorium/plutonium mixed oxides. J. Nucl. Mater. 416, 135-141.

Driscoll, M.J., Downar, T.J., Pilat, E.E., 1991. The Linear Reactivity Model for Nuclear Fuel Management. American Nuclear Society, La Grange Park, IL.

Dziadosz, D., Ake, T.N., Saglam, M., 2004. Weapons-grade plutonium-thorium PWR assembly design and core safety analysis. Nucl. Technol. 147, 69-83.

Ellis, R.J., 2000. System Definition Document: Reactor Data Necessary for Modeling Plutonium Disposition in Catawba Nuclear Station Units 1 and 2. Technical Report ORNL/TM-1999/255. Oak Ridge National Laboratory. Oak Ridge, TN.

Forsberg, C.W., Hopper, C.M., Vantine, H.C., 1999. What is non-weapons-usable uranium-233?, in: Nonproliferation Issues in Fuel Cycle Analysis and Downblending, ANS 1999 Winter Meeting, Long Beach, CA.

Fridman, E., Kliem, S., 2011. Pu recycling in a full Th-MOX PWR core. Part I: Steady state analysis. Nucl. Eng. Des. 241, 193-202.

Galperin, A., 1995. Utilization of light water reactors for plutonium incineration. Ann. Nucl. Energy 22, $507-511$.

Galperin, A., Raizes, G., 1997. A pressurized water reactor design for plutonium incineration: Fuel cycle options. Nucl. Technol. 117, 125-132.

Ganda, F., Greenspan, E., 2010. Analysis of reactivity coefficients of hydride-fueled PWR cores. Nucl. Sci. Eng. 164, 1-32.

Haas, D., Hamilton, D.J., 2007. Fuel cycle strategies and plutonium management in Europe. Prog. Nucl. Energy 49, 574-582.

Herman, B., 2009. Achieving High Burnup with Thorium-Plutonium Fuel. 22.251 Systems Analysis of the Nuclear Fuel Cycle. Massachusetts Institute of Technology, Cambridge, MA.

Hesketh, K., 2013. The potential role of the thorium fuel cycle in reducing the radiotoxicity of long-lived waste, in: Proc. WM2013 Conference, Phoenix, AZ.

Hutt, P.K., Gaines, N., Halsall, M.J., McEllin, M., White, R.J., 1991. The UK core performance code package. Nucl. Energy 30, 291-298.

IAEA, 2002. Thorium Fuel Utilization: Options and Trends. Technical Report IAEA-TECDOC-1319. International Atomic Energy Agency. Vienna, Austria. 
IAEA, 2003. Potential of Thorium Based Fuel Cycles to Constrain Plutonium and Reduce Long Lived Waste Toxicity. Technical Report IAEA-TECDOC-1349. International Atomic Energy Agency. Vienna, Austria. IAEA, 2005. Thorium Fuel Cycle - Potential Benefits and Challenges. Technical Report IAEA-TECDOC1450. International Atomic Energy Agency. Vienna, Austria.

IThEO, 2015. International Thorium Energy Organisation. URL: http://www.thoriumenergyreport. org/.

Joo, H.K., Kim, Y.J., 2000. Potential of thorium-based fuel cycle for 900MWe PWR core to constrain Pu and to reduce long-term toxicity, in: Proc. Korean Nuclear Society Autumn Meeting, Taejon, Korea.

Kozlowski, T., Downar, T.J., 2007. PWR MOX/UO ${ }_{2}$ Core Transient Benchmark. Technical Report NEA/NSC/DOC(2006)20. OECD Nuclear Energy Agency, Nuclear Science Committee. Paris, France.

Lombardi, C., Mazzola, A., Padovani, E., Ricotti, M.E., 1999. Neutronic analysis of U-free inert matrix and thoria fuels for plutonium disposition in pressurised water reactors. J. Nucl. Mater. 274, 181-188.

Martin, J.E., 2013. Physics for Radiation Protection. Wiley-VCH Verlag \& Co., Weinheim, Germany.

Newton, T., Hosking, G., Hutton, L., Powney, D., Turland, B., Shuttleworth, T., 2008. Developments within WIMS10, in: Proc. PHYSOR 08, Interlaken, Switzerland.

NRC, 2016. NRC Regulations Title 10, Code of Federal Regulations. Appendix A to Part 50, Criterion 11 of Protection by Multiple Fission Product Barriers. Nuclear Regulatory Commission, Washington, DC.

Parks, G.T., Knight, M.P., 1995. PWR fuel management using PANTHER, in: Proc. Fuel Management and Handling, Edinburgh, UK. pp. 19-24.

Puill, A., 1999. Thorium Utilization in PWRs. Neutronics Studies, in: Thorium Fuel Utilization: Options and Trends. Proceedings of Three IAEA Meetings Held in Vienna in 1997, 1998 and 1999. Technical Report IAEA-TECDOC 1319. International Atomic Energy Agency. Vienna, Austria.

Radford, K.C., Argall, B.M., Keller, H.W., Goodspeed, R.C., 1982. Fabrication development and application of an annular $\mathrm{Al}_{2} \mathrm{O}_{3}-\mathrm{B}_{4} \mathrm{C}$ burnable absorber. Nucl. Technol. 60, 344-351.

Shwageraus, E., Feinroth, H., 2011. Potential of silicon carbide cladding to extend burnup of Pu-Th mixed oxide fuel. Trans. Am. Nucl. Soc. 104, 658-660.

Shwageraus, E., Hejzlar, P., Kazimi, M., 2004. Use of thorium for transmutation of plutonium and minor actinides in PWRs. Nucl. Technol. 147, 53-68.

Simmons, R.L., Jones, N.D., Popa, F.D., Mueller, D.E., Pritchett, J.E., 1987. Integral fuel burnable absorbers with $\mathrm{ZrB}_{2}$ in pressurized water reactors. Nucl. Technol. 80, 343-348.

Sukjai, Y., Kazimi, M.S., 2015. Performance of thoria fuels and SiC cladding for burning of plutonium in pressurized water reactors, in: Proc. ANFM2015, Hilton Head, SC.

Trellue, H.R., Bathke, C.G., Sadasivan, P., 2011. Neutronics and material attractiveness for PWR thorium systems using Monte Carlo techniques. Prog. Nucl. Energy 53, 698-707.

Tsige-Tamirat, H., 2011. Neutronics assessment of the use of thorium fuels in current pressurized water reactors. Prog. Nucl. Energy 53, 717-721.

Wang, D., Kazimi, M.S., Driscoll, M.J., 2003. Optimization of a Heterogeneous Thorium-Uranium Core Design for Pressurized Water Reactors. Technical Report MIT-NFC-TR-057. Massachusetts Institute of Technology, Nuclear Fuel Cycle Program. Cambridge, MA.

Weaver, K., Herring, J.S., 2004. Performance of thorium-based mixed-oxide fuels for the consumption of plutonium in current and advanced reactors. Nucl. Technol. 143, 22-36. 